clusive as they appeared in 1935. Later work (for example, ref. 3, but chiefly unpublished) has included very detailed analyses in which atomic positions have been fixed to rather better than $0 \cdot 1 \mathrm{~A}$., and within this limit there is no evidence that the pyranose ring departs from the Sachse trans conformation; this is not to say that I believe that small deviations from exactly tetrahedral bond angles are necessarily excluded or indeed improbable, but since the possible combinations of deviations are so numerous, it would seem to be advisable to restrict speculations on the structure of cellulose to tetrahedral configurations until experimental evidence requires some departure from them.

While I believe that the structure of cellulose will best be determined, as suggested by Peirce, by combining the knowledge of atomic arrangements found in crystalline oligosaccharides with the less detailed information obtained from cellulose itself, it must be emphasized that the assignment of atomic parameters in cellulose with an accuracy of $0.01 \mathrm{~A}$. is at present entirely speculative ${ }^{4}$, since the most detailed saccharide crystal analysis so far reported ${ }^{3}$ gives atomic positions only to about $0.08 \mathrm{~A}$., and the data from cellulose itself certainly do not justify any higher accuracy.

The Frythe,

E. G. Cox.

Welwyn,

Herts.

${ }^{1}$ Nature, 158, 586 (1944).

'Cox, Goodwin and Wagstaff, J. Chem. Soc., 1495 (1935).

$3 \mathrm{Cox}$ and Jeffrey, Nature, 148, 894 (1939).

'Cf. Cox, Ann. Rep. Chem. Soc., 34, 194 (1937).

\section{Thermodynamics of Friedel-Crafts , Reactions}

SINCE the time of Gustarson ${ }^{1}$ and Menschutkin ${ }^{2}$ it has been known that salts of the $\mathrm{AlCl}_{3}$ type can give stable complex compounds with certain classes of organic compound.

We have measured the heats of formation from the salt plus organic liquid of a number of these complexes. A Dewar-vessel calorimeter was used, and the results were corrected for spurious heat effects, such as those arising from chemical reactions other than complex formation. In some cases the heats are surprisingly large, and, neglecting entropy effects, it has seemed reasonable to us to ascribe an important role in these cases to the complex-formation stage, in controlling the course and products of the reaction.

For example, consider the two reactions below

$\mathrm{COg}+\mathrm{C}_{6} \mathrm{H}_{6} l=\mathrm{C}_{6} \mathrm{H}_{5} \mathrm{CHO} l$. catalysed by 1 mole of $\mathrm{AlBr}_{3}$

$n \mathrm{CH}_{3} \mathrm{Cl} g+\dot{\mathrm{C}}_{6} \dot{\mathrm{H}}_{6} l=\dot{\mathrm{C}}_{6} \dot{\mathrm{H}}_{6-n}\left(\dot{\mathrm{CH}}_{3}\right)_{n} \dot{l}+n \dot{\mathrm{HC}} \dot{\mathrm{l}}$ catalysed

by a small amount of $\mathrm{AlCl}_{3}$

Calculation from heat of combustion and entropy data yields values of $\Delta G^{\circ}$ for both reactions in the neighbourhood of zero (restricting ourselves to the case $n=1,2$ and 3 in reaction 2). There is an uncertainty in the heats of combustion which gives an error of perhaps \pm 1 kcal. in case 1 , and a possibly larger error in reaction 2, due to the uncertain data for $\mathrm{CH}_{3} \mathrm{Clg}$. This uncertainty is not likely to affect the point we wish to make.

In both cases no stable complex is formed between the catalyst and the reactants, and we are concerned with the products only. Considering reaction 1 , we have found that the heat of formation of the complex
$\mathrm{AlBr}_{3}\left(\mathrm{C}_{6} \mathrm{H}_{5} \mathrm{CHO}\right)_{x}$ is $30 \mathrm{kcal}$. per mole of aluminium bromide. It therefore seems reasonable to suggest that this complex-formation, by making the overall free energy of reaction strongly negative, plays a large part in ensuring the excellent yields normally obtainable in this reaction ${ }^{3}$.

Our calculation for reaction 2 would suggest that, complex formation apart, none of the possible products toluene, xylenes, trimethylbenzenes should be specially favoured on thermodynamic grounds. This view is supported by the observations of Boedtker and Halse ${ }^{4}$, on the reversibility of this reaction, carried out under normal liquid-phase conditions. However, we find that the heats of complex forma. tion are $\mathrm{AlCl}_{3} /$ xylene 22 kcal.; $\mathrm{AlCl}_{3} /$ mesitylene 8 kcal.; and $\mathrm{AlCl}_{3} /$ toluene 0 kcal. Clearly, we should expect the preferential formation of the $\mathrm{AlCl}_{3} / \mathrm{xylene}$ complex, and this in fact may be found under special conditions. If methyl chloride gas is passed over aluminium chloride in a vertical catalyst. tube, xylene is preferentially obtained as the $\mathrm{AlCI}_{3} / \mathrm{xylen} \theta$ complex. This drips from the tube, leaving a fresh aluminium chloride surface. On the other hand, if the xylene/ $/ \mathrm{AlCl}_{3}$ complex be retained in the sphere of action by using a horizontal catalyst tube, appreciable yields of toluene may be obtained. In this latter case, similar to the usual liquid phase conditions, the xylene/ $\mathrm{AlCl}_{3}$ complex is formed initially, and then itself functions as a catalyst.

It is well known that the quantity of 'catalyst' used plays an important part in Friedel-Crafts syntheses; for example, whereas reaction 2 needs only small amounts, reaction 1 requires a molar quantity. Our work would suggest that two conditions determine this quantity : first, whether complex formation is necessary to make the reaction thermodynamically favourable; secondly, if a com. plex is formed, whether it is catalytically active. In the quantitative investigation of any particular synthesis, both factors require consideration. Equilibrium constants obtained by using catalysts of the type of aluminium chloride must be suspect unless they have been shown to be independent of catalyst concentration (for example, Pitzer's work on the xylene plus benzene reaction ${ }^{5}$.

Approval for publication has been granted by the Director-General of Scientific Research and Development, Ministry of Supply.

H. Campbeli.

Department of Colloid Science, D. D. Eley. University, Cambridge. May 12.

${ }^{1}$ Gustavson, J. Prak. Chemie, 68, 209 (1903); 72, 57 (1905). Menschutkin, Chem. Ab8., 8, 1487 (1909); 5, 1434 (1911).

- Reformatsky, Chem. Zent., (i), 1226 (1901); (ii), 1372 (1901).

- Boedtker and Halse, Bull. Soc. Chim., 19, 444 (1916).

- Pitzer and Scott, J. Amer. Chem. Soc., 65, 803 (1943).

\section{Reabsorption of Electrolytes in the Renal Tubules}

REABSORPTION of electrolytes in the renal tubules has been examined for phosphates by Harrison and Harrison ${ }^{1}$ and Smith, Ollayas and Winkler ${ }^{2}$ in the dog, and by Barclay, Bray and Cooke ${ }^{3}$ in man, and for chlorides by Hare, Hare and Phillips ${ }^{4}$.

An examination of the available data at this stage may provide indication for future work and perhaps a basis for some standard system of imparting results. 